\title{
Analysis of Genetic Diversity in Kale (Brassica oleracea L. var. acephala) Genotypes of Jammu and Kashmir Region based on Morphological Descriptors
}

\author{
Sunnia Gorka*, R.K. Samnotra, Sanjeev Kumar, \\ Sandeep Chopra and Moni Gupta
}

\author{
Faculty of Agriculture, Sher-e-Kashmir University of Agricultural Sciences and Technology of \\ Jammu, Chatha J\&K, India \\ *Corresponding author
}

\begin{tabular}{|l|}
\hline Ke y w or d s \\
Brassica oleracea, \\
Genetic diversity, \\
Kale
\end{tabular}

\section{A B S T R A C T}

The present investigation entitled analysis of genetic diversity in kale genotypes of Jammu and Kashmir region based on morphological descriptors was carried out in order to reveal the available genetic diversity present in kale genotypes collected from the different kale growing regions of the J\&K state including Jammu, Kashmir and Leh and to select the elite genotypes that possess superior leaf yield attributing traits and quality traits. Remarkable variability was present among genotypes for various leaf attributes. However, there is probability of duplicates being present in above collection. Hence, morphological characterization is resorted to identify the duplicates. Therefore, these collected genotypes were laid out at Vegetable Experimental Farm, Sher-e-Kashmir University of Agricultural Sciences and Technology, Chatha, Jammu and data were recorded on traits namely plant height revealed that $20(66.67 \%)$ genotypes had tall plant height, 5(16.67\%) genotypes had medium height and 5(16.67\%) genotypes are of short height. Plant shape at peak leaf picking stage revealed that $13(43.34 \%)$ were found to be dome shaped, 10 were of inverted pyramid shape and $(23.34 \%)$ and 7 (23.34\%) genotypes were of column shape. Leaf blade color at fully developed leaf stage revealed that 25 (83.34\%) genotypes among 30 were found to be green in color while 4 (13.34\%) genotypes were blue-green in color and only one genotype was found to be of purple color. Leaf type was categorized as entire or lobed with lobed observed in $14(46.67 \%)$ genotypes and entire in $16(53.34 \%)$ genotypes. Leaf shape showed variation from very narrow elliptic, narrow elliptic to elliptic with 11 $(36.67 \%)$ genotypes very narrow elliptic and $4(13.34 \%)$ being elliptic.

\section{Introduction}

Kale (Brassica oleracea L. var. acephala DC.) is one of the oldest forms of the cabbage family and is probably the first brassicas to be cultivated which are quite similar to wild cabbage. It is quite similar to cabbage and is a green leafy vegetable in which central leaves do not form head. Kale has originated from eastern Mediterranean region and is being used as a food crop since 2000 BC (Acikgoz, 2011). Cabbage and other brassicas are at present grown extensively throughout all the parts of the world over an area of 2470.27 
thousand hectares with a productivity of 29.05 tonnes/hectare. In India, it is being grown over an area of 400.14 thousand hectares with a productivity of 22.59 tonnes/hectare (Anonymous, 2014a). Among the leafy vegetables, kale is cultivated on a large scale in the temperate regions of our country like J\& K, HP and to limited extents in North-East region. In Kashmir, it is grown in almost all kitchen gardens and also as a commercial crop around cities and towns (Khan et al., 2009). Kale grown there is popularly known as "HAK" (Wanchoo, 2000). In Jammu and Kashmir, it is being grown over an area of 2460 hectares out of which in Jammu region it occupies an area of 160 hectares with a productivity of 18.78 tonnes/hectare (Anonymous, 2014b).

In Asaba, Delta State of Nigeria, kale is nicknamed "hospital too far". This is because of the health benefits of kale. It is a very nutritious vegetable, rich in vitamins and minerals particularly vitamin $\mathrm{C}$, pro-vitamin ( $\beta$-carotene $\&$ lutein) and minerals and anti oxidants (Cao et al., 1996). It is one of the richest source of carotenoids especially xanthophylls (Ligor and Buszewski, 2012). Among all 100 of the worlds healthiest foods, kale grabs the first position in terms of lutein content and is the primary lutein-containing food in the USDA's National Nutrient Database that analyzes 5,350 foods that contain this carotenoid nutrient. Kale is a potent source of glucosinolates and contains about 15-20 different glucosinolates like compounds (Sikora et al., 2007). These glucosinolates are sulfur containing compounds that are mainly synthesized in crucifers, and reduce the risk of several forms of (Francisco et al., 2011).

Kale is a highly cross pollinated vegetable crop. It is grown under all the agro climatic conditions from subtropical, temperate to cold arid zones of the $J \& K$ state. It is one of the hardiest crop and is highly resistant to low temperatures and can even survive at a low temperature of $-15^{\circ} \mathrm{C}$ (Altinok and Karakya, 2003). The crop is reported rich in diversity due to complex natural intra and inters specific crosses and geographical barriers. Genetic diversity of North West Himalayan region has not been properly documented and characterized for further use in any plant breeding programme.

Thus, there is a need for exploration and conservation of existing diversity among the conservation of existing diversity among the available genotypes grown in this region. Therefore, present study was conducted on kale genotypes collected from different areas of Chennani, Assar, Karlah, Kupwara, Pulwama, Bandipura, Drass, Leh, Kashmir and Jammu.

\section{Materials and Methods}

The present investigation was carried out in the year 2015-16 in which kale thirty genotypes were firstly collected from the various kale growing regions of the J\&K state namely Chennani, Assar, Karlah, Kupwara, Pulwama, Bandipura, Drass, Leh, Kashmir and Jammu and laid out in Vegetable Experimental Farm, Sher-e-Kashmir University of Agricultural Sciences and Technology, Chatha, Jammu. The experimental field of Division of Vegetable Science and Floriculture, SKUAST, Jammu is situated at $32^{\circ} 40^{\prime} \mathrm{N}$ latitude and $74^{\circ} 58^{\prime} \mathrm{E}$ longitude and has an elevation of $332 \mathrm{~m}$ above mean sea level. Agro climatically the location represents Zone V of Jammu and Kashmir and is characterized by subtropical climate. The place experiences hot dry summer, hot and humid rainy season and cold winter months, the maximum temperature goes up to $45^{\circ} \mathrm{C}$ during summers (May to June) and minimum temperature falls to $1^{\circ} \mathrm{C}$ during winters. Codes were allotted to each genotypes on the basis of their location (as SJKK stands for SKUAST-Kashmir kale 
selection, SJKKP stands for Kupwara kale selection, SJKC for CITH kale selection, SJKB for Bandipura kale selection, SJKL for Leh kale selection, SJKLJ for Jammu local kale selection, SJKD for drass kale selection, SJKP for Pulwama kale selection). Observations were recorded at the time of third leaf picking stage of the plant growth using descriptors given by UPOV (International union for the protection of new varieties of plants) guidelines published in 2014 (UPOV). Plant height was observed as overall height attained by the plant during the peak leaf picking stage as 3 (short), 5 (medium) and 7 (tall). The plant shape was observed as overall shape attained by the plant and was graded as 1 (inverted pyramid), 3 (dome), and 5 (column). Leaf blade was visually observed as the color of fully developed leaf as 2 (green), 4 (blue green), 6 (red or purple). Leaf type observed as 1 (entire) and 9 (lobed). Leaf blade observes as shape for varieties with curled leaves only with 1 (very narrow elliptic), 3 (narrow elliptic) and 5 (elliptic).

\section{Results and Discussion}

Plant characteristics of leafy kale are of immense importance as far as the diversity is concerned. Present study revealed wide diversity among the kale genotypes collected after surveying of different locations of $J \& K$ state.

On the basis of the results present in the plant height (Table 1 and 2) the genotypes varied between small, medium and tall. Out of 30 Kale genotypes studied $20 \quad(66.67 \%)$ genotypes had tall plant height, $5(16.67 \%)$ genotypes had medium height and $5(16.67 \%)$ genotypes are of short height. Maximum genotypes had tall height. Tall height may attribute towards its genetic constitution. Plant shape at peak leaf picking stage revealed that out of 30 genotypes studied $13(43.34 \%)$ were found to be dome shaped,
10 were of inverted pyramid shape and $(23.34 \%)$ and $7(23.34 \%)$ genotypes were of column shape. This showed that with regard to plant shape the variability observed among genotypes is high. Leaf blade color at fully developed leaf stage revealed that 25 (83.34\%) genotypes among 30 were found to be green in color while $4(13.34 \%)$ genotypes were blue-green in color and only one genotype was found to be of purple color. Leaf type was categorized as entire or lobed with lobed observed in 14 (46.67\%) genotypes and entire in 16 (53.34\%) genotypes. Leaf type was in almost half proportion in both the genotypes (Table 3 ).

Leaf shape showed variation from very narrow elliptic, narrow elliptic to elliptic with $11(36.67 \%)$ genotypes very narrow elliptic and $4(13.34 \%)$ being elliptic and rest of the genotypes were not curly. Similar studies when done by Stoilova et al., (2014) on morphological descriptors of amaranthus revealed that Amaranth accessions showed possessed an erect growth habit except for accessions Kongei, UG-AM 21 and AC-45, which had a prostrate growth habit. Also, Erum et al., (2012) working on amaranthus accessions diversity concluded that amaranth accessions with a higher number of branches have the potential to produce high leaf yield. The color of amaranth stems was predominantly a mix of green and red color for $48 \%$ of accessions, purple to pink for $32 \%$, and green and white color for $20 \%$. Similarly work when done by Shimoya et al., (2002), evaluating the diversity in the elephantgrass germplasm bank based on 17 morphological descriptors, observed that the last five canonic variables presented a variance lower than 0.7 and that the characteristics of greatest weight were, in decreasing order, stem diameter, leaf width in the middle of the adult mean leaf, leaf width in the base of the adult mean leaf, awn length and spikelet length. 
Table.1 Plant and leaf characteristics of kale (Brassica oleracea L. var. acephala) genotypes

\begin{tabular}{|c|c|c|c|c|c|c|c|c|c|c|}
\hline S.no. & Genotypes & \multicolumn{2}{|c|}{$\begin{array}{l}\text { Plant } \\
\text { Height }\end{array}$} & $\begin{array}{l}\text { Plant } \\
\text { Shape }\end{array}$ & \multicolumn{2}{|c|}{$\begin{array}{l}\text { Leaf Blade } \\
\text { color }\end{array}$} & \multicolumn{2}{|c|}{ Leaf type } & \multicolumn{2}{|c|}{ Leaf blade } \\
\hline 1. & SJKK-1 & \multicolumn{2}{|c|}{7} & 3 & \multicolumn{2}{|c|}{4} & \multicolumn{2}{|l|}{9} & \multicolumn{2}{|l|}{1} \\
\hline 2. & SJKKP-1 & \multicolumn{2}{|l|}{7} & 3 & \multicolumn{2}{|l|}{2} & \multicolumn{2}{|l|}{9} & \multicolumn{2}{|l|}{1} \\
\hline 3. & SJKC-1 & \multicolumn{2}{|l|}{7} & 3 & \multicolumn{2}{|l|}{4} & \multicolumn{2}{|l|}{9} & \multicolumn{2}{|l|}{1} \\
\hline 4. & SJKB-1 & \multicolumn{2}{|l|}{7} & 3 & \multicolumn{2}{|l|}{2} & \multicolumn{2}{|l|}{9} & \multicolumn{2}{|l|}{1} \\
\hline 5. & SJKJ-1 & \multicolumn{2}{|l|}{7} & 3 & \multicolumn{2}{|l|}{4} & \multicolumn{2}{|l|}{9} & \multicolumn{2}{|l|}{1} \\
\hline 6. & SJKK-2 & \multicolumn{2}{|l|}{7} & 5 & \multicolumn{2}{|l|}{2} & \multicolumn{2}{|l|}{9} & \multicolumn{2}{|l|}{1} \\
\hline 7. & SJKKP-2 & \multicolumn{2}{|l|}{7} & 5 & \multicolumn{2}{|l|}{4} & \multicolumn{2}{|l|}{9} & \multicolumn{2}{|l|}{1} \\
\hline 8. & SJKC-2 & \multicolumn{2}{|l|}{7} & 5 & 2 & & 9 & & 1 & \\
\hline 9. & SJKB-2 & 7 & & 5 & 2 & & 9 & & 1 & \\
\hline 10. & SJKJ-2 & 7 & & 5 & 2 & & 9 & & 1 & \\
\hline 11. & SJKL-1 & 3 & & 1 & 2 & & 1 & & - & \\
\hline 12. & SJKL-2 & 7 & & 3 & 2 & & 1 & & - & \\
\hline 13. & SJKL-1 & 7 & & 1 & 2 & & 1 & & - & \\
\hline 14. & SJKL-2 & 7 & & 1 & 2 & & 1 & & - & \\
\hline 15. & SJKL-3 & 7 & & 1 & 2 & & 1 & & - & \\
\hline Legends & & & & & & & & & & \\
\hline $\begin{array}{c}\text { Plant } \\
\text { height }\end{array}$ & Note & $\begin{array}{l}\text { Plant } \\
\text { shape }\end{array}$ & Note & $\begin{array}{l}\text { Leaf blade } \\
\text { color }\end{array}$ & Note & $\begin{array}{l}\text { Leaf } \\
\text { type }\end{array}$ & Note & & $\begin{array}{l}\text { eaf blade } \\
\text { shape }\end{array}$ & Note \\
\hline Short & 3 & $\begin{array}{l}\text { Inverted } \\
\text { pyramid }\end{array}$ & 1 & green & 2 & entire & 1 & & $\begin{array}{l}\text { ery narrow } \\
\text { elliptic }\end{array}$ & 1 \\
\hline Medium & 5 & Dome & 3 & Blue green & 4 & Lobed & 9 & & row elliptic & 3 \\
\hline Tall & 7 & Column & 5 & $\begin{array}{l}\text { Red or } \\
\text { purple }\end{array}$ & 6 & & & & elliptic & 5 \\
\hline
\end{tabular}

Table.3 Summary of frequency of leaf and plant characteristics of kale genotypes

\begin{tabular}{|c|c|c|c|}
\hline Plant characteristics & Category & No. of genotypes & Percentage \\
\hline Plant height & Short & 5 & 16.67 \\
\hline & Medium & 5 & 16.67 \\
\hline & Tall & 20 & 66.67 \\
\hline Plant shape & Inverted pyramid & 10 & 33.34 \\
\hline & Dome & 13 & 43.34 \\
\hline & Column & 7 & 23.34 \\
\hline Leaf blade & green & 25 & 83.34 \\
\hline & Blue green & 4 & 13.34 \\
\hline & Red or purple & 1 & 3.34 \\
\hline Leaf type & entire & 16 & 53.34 \\
\hline & Lobed & 14 & 46.67 \\
\hline Leaf blade shape & Very narrow elliptic & 8 & 26.67 \\
\hline & Narrow elliptic & 11 & 36.67 \\
\hline & elliptic & 11 & 36.67 \\
\hline
\end{tabular}


Table.2 Plant and leaf characteristics of kale (Brassica oleracea L. var. acephala) genotypes

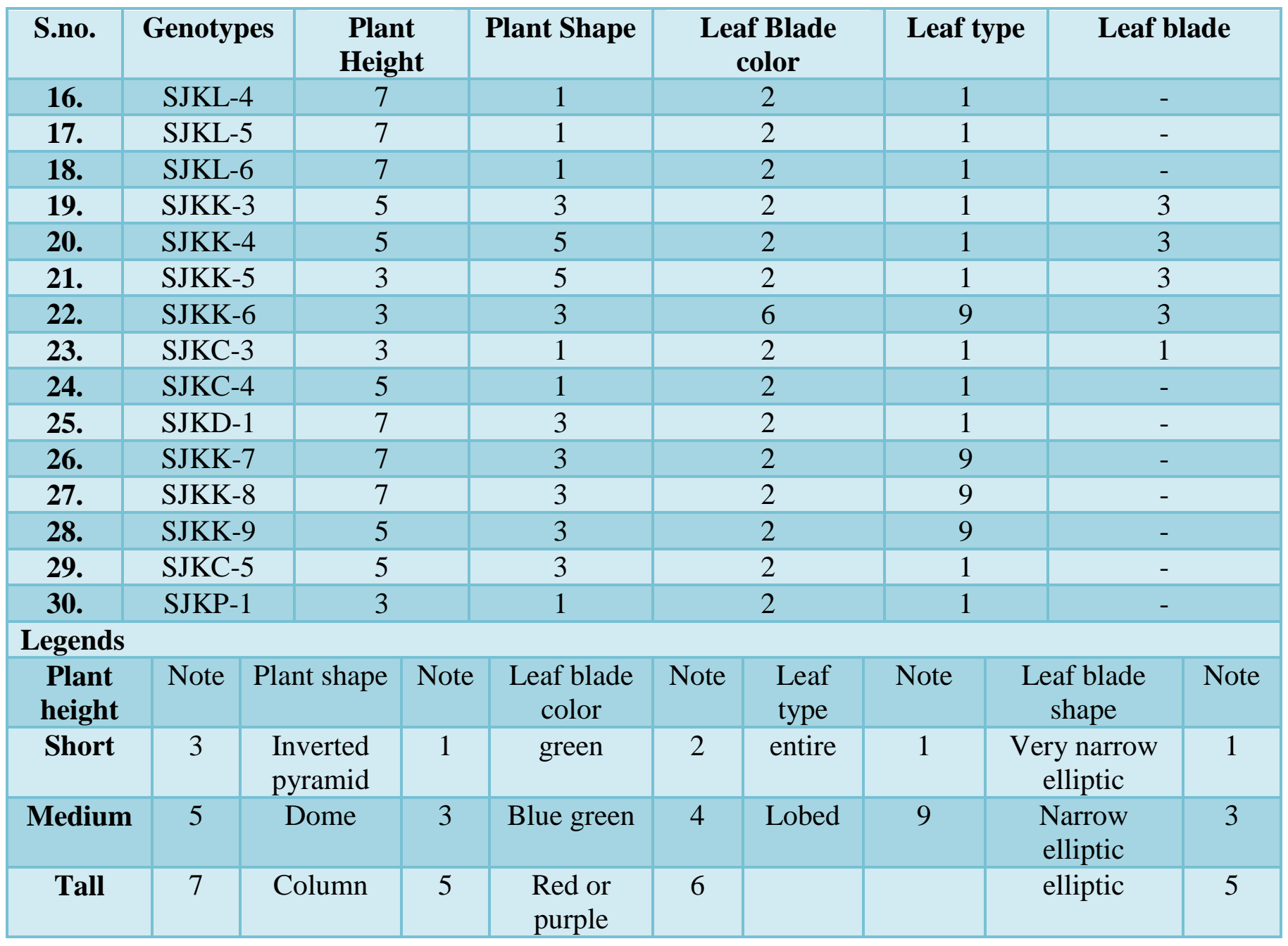

From the results it is evident that based on morphological characters, wide variability was observed in both the crops. this variability can be accounted by the fact that kale genotypes present in this region can be further used in various kale improvement programs and thus, the variability needs to be conserved for all future breeding programs and should be documented.

\section{References}

Acikgoz, F. E. 2011. Mineral, vitamin C and crude protein contents in kale (Brassica oleraceae var. acephala) at different harvesting stages. African Journal of
Biotechnology, 10(75): 17170-17174.

Altinok, S. and Karakaya, A. 2003. Effect of growth season on forage yields of different Brassica cultivars under Ankara conditions. Turkish Journal of Agriculture and forestry, 27: 85-90.

Anonymous 2014a. FAOSTAT 2014, "FAO Statistics, Food and Agriculture Organization of the United Nations," Rome, 2012. http://faostat.fao.org/

Anonymous 2014b. Area and production of crop in J\&K. Annual report, Department of Agriculture, Jammu. pp. 89.

Cao, G., Sofic, E. and Prior, R. L. 1996. Antioxidant capacity of tea and 
common vegetables. Journal of agricultural food chemistry, 44: 34263431.

Erum, S., Naeemullah, M., Masood, S., Qayyum, A., and Rabbani, A.M. (2012). Genetic divergence in Amaranthus collected from Pakistan. The Journal of Animal \& Plant Science 22, 653-658.

Francisco, M., Cartea, M. E., Soengas, P. and Velasco, P. 2011. Effect of genotype and environmental conditions on healthpromoting compounds in Brassica rapa. Journal of Agricultural and Food Chemistry, 59: 2421-2431.

Khan, S. H., Ahmed, N., Jabben, N., Mushtak, F. and Hussain, K. 2009. Genetic divergence in kale (Brassica oleracea var. acephala). The Asian Journal of Horticulture, 4(1): 134-137.

Ligor, M. and Buszewski, B. 2012. Effect of Kale Cultivation Conditions on Biosynthesis of Xanthophylls. Journal of Food Research. 1(4): 74-84.

Shimoya, A. Cruz, C. D., Ferreira, R.P. (2002) Divergência genética entre acessos deum banco de germoplasma de capim-elefante. Pesquisa Agropecuária Brasileira, 37(7): 971-980.

Sikora, E., Cieslik, E., Leszczynska, T., Filipiak-Florkiewicz, A., Pisulewski, P. M. 2007. The antioxidant activity of selected cruciferous vegetables subjected to aquathermal processing. Food Chemistry, 107(1):55-59.

Stoilova, T., Dinssa, F. F., Elbert, A. W. and Tenkouano, A. 2014. The diversity of African leafy vegetables agromorphological collocations of sunsets of AVRDC's germplasm collection. Acta Horticulturae, 4: 67-74.

UPOV, 2004. International union for the protection of plants. Guidelines for the conduct of tests for distinctness, uniformity and stability. Kale (Brassica oleracea L. var. acephala). UPOVTG/Kale. Geneva, pp. 1-25

Wanchoo, P. N. 2000. Horticulture in Himalayas principle and practices. Bishen Singh Mahendra Pal Singh Dehradun, India. pp. 266.

\section{How to cite this article:}

Sunnia Gorka, R.K. Samnotra, Sanjeev Kumar, Sandeep Chopra and Moni Gupta. 2018. Analysis of Genetic Diversity in Kale (Brassica oleracea L. var. acephala) Genotypes of Jammu and Kashmir Region based on Morphological Descriptors. Int.J.Curr.Microbiol.App.Sci. 7(02): 2176-2181. doi: https://doi.org/10.20546/ijcmas.2018.702.261 